\title{
Effect of Plant Debris Removal on the Incidence of Rice Sheath Blight Disease in Bangladesh
}

\author{
S Parveen ${ }^{1^{*}}$, M S Hossain ${ }^{2}, \mathrm{M} \mathrm{A} \mathrm{Ali}^{3}$ and M A Ali ${ }^{4}$
}

\begin{abstract}
Sheath blight caused by Rhizoctonia solani is a major disease of rice (Oryza sativa L.) in Bangladesh that affects the crop in almost every season. The effect of floating debris removal on the incidence of sheath blight was assessed from the previously infected fields of three upazilas of Rajshahi district during T. Aman 2010. Each field was divided into two plots. Floating debris were removed from one plot while the other plot remained unremoved. Percent hill infection was higher in control plots from where floating debris were not removed (FDNR) than that of FDR plots from where floating debris were removed from the fields of Tanore, Godagari and Paba at 35 days after transplanting. The percent hill infection was 8.89\% in FDR plots and 56.67\% in FDNR in Tanore with a difference of $47.78 \%$. Maximum $63.01 \%$ reduction in hill infection was found in Tanore between FDR and FDNR, whereas significant reduction in hill infection was found in Godagari $(46.75 \%)$ at maximum tillering stage. The reduction in the incidence of sheath blight was 51.08\% in Paba at maturity stage due to removal of floating debris from the field before transplanting. The average yield of three fields was $4.79 \mathrm{t} \mathrm{ha}^{-1}$ in FDR plot, whereas in FDNR, it was $4.18 \mathrm{t}$ ha- 1 in Tanore. Thus there was an yield difference of $0.61 \mathrm{t}$ ha- 1 in between FDR and FDNR plots. However, there was negative relationship between tiller infection and grain yield of rice. It is evident that the regression equation that the grain yield was $6.75 \mathrm{t}$ ha- 1 in the FDNR plots when there was no infections but infection in the tillers reduced the grain yield by 0.41 unit for every unit increase in tiller infection.
\end{abstract}

Key words: Plant debris, sheath blight, rice

\section{INTRODUCTION}

Bangladesh agriculture involves food production for 163.65 million people (Salam et al., 2014). Since independence, there has been a three-fold increase in rice production in Bangladesh, which jumped from nearly 11 MT in 1971-72 to about 34.86 MT in 2014-15 (AIS, 2016). Rice production area in Bangladesh during 2017-18 was 11.01 million hectare of land in which nearly 36.27 million tons of rice was produced (AIS, 2019). In the last few years (2009-10 to 2013-14), rice production has increased by 0.34 MT per year (BBS, 2014).

In Bangladesh, rice covers about $80 \%$ of cultivable land (Anonymous, 2006a). Again, $20.8 \%$ of the plant populations are being infected by the disease (Anonymous, 2006b).
Among the diseases, sheath blight is one of the major rice disease in Bangladesh.

Sheath blight $(\mathrm{ShB})$ of rice was first reported in Japan by Miyakie in 1910. It is caused by Rhizoctonia solani Kuhn. It is considered as the most damaging and major epidemic disease of rice ( $\mathrm{Li}$ et al., 2012). During offseason, pathogen survives as sclerotia or mycelia, or both, in soil or plant debris and on weeds in rice growing regions (Kumar et al., 2012). Sclerotium is the primary inoculum that overwinters and infects the subsequent rice crop. Under favourable conditions, ShB spreads rapidly through mycelia in all directions (Su et al., 2012). Rhizoctonia solani is a universal soil saprotrophic and facultative plant parasite (Ogoshi, 1996; Anees et al., 2010). It survives in soil as sclerotia (Tsai et al., 2012). Rhizoctonia

${ }^{1}$ Senior Scientific Officer and ${ }^{2}$ Principal Scientific Officer, Training Division, BRRI, Gazipur 1701 and ${ }^{3}$ Professor, Department of Plant Pathology, Faculty of Agriculture, BAU, Mymensingh and ${ }^{4}$ Director (Administration and Common Service), BRRI, Gazipur 1701. *Corresponding author's E-mail: parveenbrri@yahoo.com 
solani survives in unfavourable conditions by forming sclerotia or dormant mycelia (Anees et al., 2010). Sclerotia spread during land preparation and flooding of the field by irrigation water (Brooks, 2007). During permanent flooding the sclerotia may float and move within or other fields through water flow. Sclerotia or hyphae attach to the plant, infecting and causing ShB disease.

In Bangladesh 31 rice diseases have been identified of which ten are considering as major (Miah and Shahjahan, 1987) and ShB perhaps the number one major disease of rice in Bangladesh. It is an important rice disease, especially in intensive rice cropping systems. Incidence and development of ShB of rice depends on weather parameter, host and soil factor (Damicone et al., 1993). Disease spread and intensity is dependent on the amount of infectious inoculum present in planting material and residues of previous crop. Large lesions formed on infected sheaths of lower leaves may lead to softness of the stem thereby initiating stem lodging ( $\mathrm{Wu}$ et al., 2012). The average incidence of ShB in Bangladesh is about 20.3\% (Ali et al., 2003). The losses caused by ShB in Bangladesh may ranges from 14 to $31 \%$ under farmer's field (Shahjahan et al., 1986). The presence of one or many factors may enhance the severity of the disease beyond economic threshold levels, thereby incurring low to high yield losses.

Disease management programme against $\mathrm{ShB}$ can concrete on different approaches such as incorporating cultural practices, exploitation of host resistance, biological control with $T$. harzianum and $T$. viride and chemical control. The control of ShB in the field so far is relied mainly on the use of fungicides by the farmers. Chemical control is not considered sustainable because of its toxic residual effect. But, there is ample scope of useing different cultural practices such as clean cultivation, soil solarization during drymonths (April-May) for management of $\mathrm{ShB}$ of rice. For clean cultivation, burning the crop residues, destroy grasses and other hosts from the field and alongside the levee or allow decomposition during land preparation, collecting and burying floating debris after final land preparation may reduce infection foci. Straw burning advocated to reduce sclerotial density in the soil and modification of cultural practices during growing stages of plants may be effective in controlling rice ShB, because the sources of inoculums are proved to be one of the most important aspects of the disease development (Sharma et al., 1994). Therefore, the present study was under taken to evaluate the effect of plant debris removal from the rice field for controlling $\mathrm{ShB}$ disease in Bangladesh.

\section{MATERIALS AND METHODS}

The experiment was conducted during $\mathrm{T}$. Aman 2010 in the farmer's fields of three upazilas namely Tanore, Godagari and Paba of Rajshahi district. In each upazila, three rice fields were selected, where size of each field was 33-50 decimal. The selected field had a history of ShB infestation. After final land preparation, floating debris were settled down at the corner of the field removed by using a sieve or a white cotton cloth. Each field was divided into two plots of equal size. Each plot was used as experimental unit. There were two experimental units in each farmer's field. One plot was designated as FDR (Floating debris removed) and another as FDNR (Floating debris not removed) (Fig. 1). Thirty-day-old and 2-3 seedlings per hill of Gutisharna were transplanted with a spacing of $20 \mathrm{~cm} \times 15 \mathrm{~cm}$. Fertilizers were applied @ 405:150:202:135:10 $\mathrm{g} /$ decimal of urea, TSP, MOP, gypsum and zinc sulphate. All fertilizers were applied in basal, except urea (Anonymous, 2010).

Nine hills were selected by putting a bamboo stick in $\mathrm{W}$ pattern (Fig. 1) at random from each of FDR and FDNR plots. Number of infected and healthy hills from nine hills at 35 


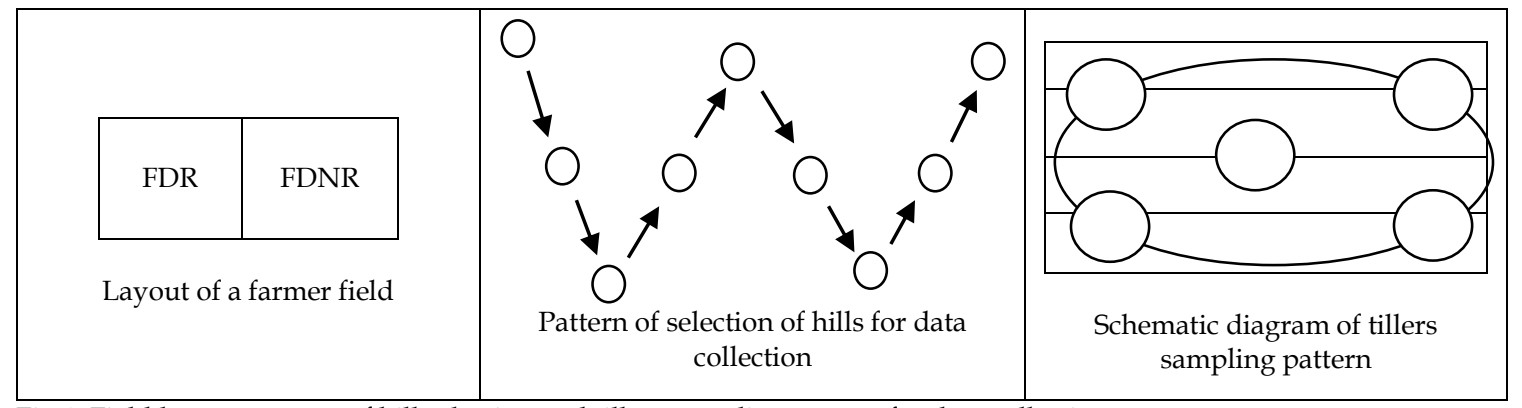

Fig 1. Field layout, pattern of hill selection and tillers sampling pattern for data collection.

DAT and maximum tillering stages and number of infected and healthy tillers from nine hills at maturity stage were counted. Data on disease incidence (\% hill infection and \% tiller infection) and yield were recorded based on five hills. Percent reduction of tiller infection due to removal of floating debris at $35 \mathrm{DAT}$, maximum tillering and maturity stage was calculated by the following formula:

No. of infected tiller in FDNR - No. of infected tiller in FDR

Reduction $(\%)=\frac{\text { No. of infected tiller in FDNR }}{\text {. }}$ $\times 100$

Paired t-test was used for analysis of the data. The mean of FDR and FDNR was compared by t-test. Different level of tiller infection was obtained from individual spot from where corresponding yield was recorded.

\section{RESULTS AND DISCUSSION}

Table 1 shows the effect of floating debris removal on the incidence of ShB disease at 35 days after transplanting (DAT). Data on ShB incidence in hill infection clearly indicate that removal of debris floating on the irrigation or rain water in the field before transplanting (after final land preparation) had significant impact on the development of rice ShB in the field. Percent hill infection was higher in control plots from where floating debris were not removed (FDNR) than that of FDR plots from where floating debris were removed from the fields of Tanore, Godagari and Paba upazila of Rajshahi district. The percent hill infection was $8.89 \%$ in FDR plots whereas in FDNR, it was $56.67 \%$ in Tanore. Thus there was a difference of $47.78 \%$ infection in between FDR and FDNR. In Godagari, the percent hill infection was $16.67 \%$ in FDR plots whereas in FDNR, it was $65.57 \%$. There was a difference of $48.9 \%$ infection in between FDR and FDNR. In Paba, percent hill infection of FDNR was $65.56 \%$ whereas in FDR, it was $13.33 \%$. The difference between FDNR and FDR was 52.23\% in Paba. Castilla et al. (1996) also studied on inoculum potential of sclerotia of Rhizoctonia solani in floating debris of rice field to measure of inoculum efficiency of rice ShB. The rate of reduction in the incidence of ShB was similar in all locations. However, there was little numerical differences. Figure 2 shows percent reduction of incidence of $\mathrm{ShB}$ at 35 DAT in FDR and FDNR plots under natural field conditions during T. Aman season. Reduction in hill infection was $84.3 \%$ in Tanore, whereas $74.57 \%$ in Godagari and $79.66 \%$ in Paba due to removal of floating debris from the field before transplanting. Hashiba and Mogi (1976) also reported that mature sclerotia detached from rice plant can survive on the surface of soil or in soil. In the following growing season, sclerotia float on the water surface, germinate and infect rice tillers. Sclerotia can survive on or in soil during the winter then germinate and infect plants (Hashiba and Mogi, 1976; Lee and Rush, 1983; Ou, 1985). 
Table 1. Effect of floating debris removal on the incidence of rice sheath blight disease ( $\%$ hill infection) at 35 DAT.

\begin{tabular}{lccc}
\hline \multirow{2}{*}{ Treatment } & \multicolumn{3}{c}{ Disease incidence (\%) } \\
\cline { 2 - 4 } & Tanore & Godagari & Paba \\
\hline FDR & 8.89 & 16.67 & 13.33 \\
FDNR (Control) & 56.67 & 65.57 & 65.56 \\
Difference & 47.78 & 48.9 & 52.23 \\
Significance & $*$ & $*$ & $*$ \\
$(\mathrm{P}=0.05)$ & & & \\
\hline DAT= Days after transplanting, FDR=Floating debris & removed \\
and FDNR=Floating debris not removed. * Significant at the 5\% \\
level by paired t-test.
\end{tabular}

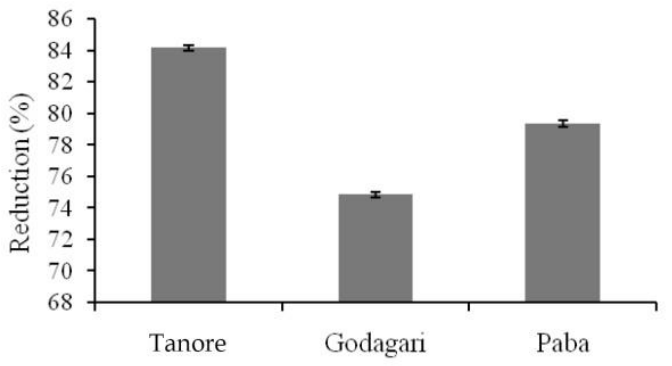

Fig. 2. Reduction of hill infection in FDR plots over FDNR in different locations at 35 DAT (FDR-Floating debris removed; FDNR-Floating debris not removed).

Table 2 shows the effect of removal of floating debris on the incidence of rice ShB at maximum tillering stage. Results on the effect of floating debris collection are observed as same as 35 DAT. Percent hill infection was higher in FDNR plot than that of FDR plot in the fields of Tanore, Godagari and Paba. The percent hill infection was 30\% in FDR plots whereas in FDNR, it was $81.11 \%$ in Tanore. Thus there was a difference of $51.11 \%$ infection in between FDR and FDNR. In Godagari, the percent hill infection was $45.56 \%$ in FDR plots whereas in FDNR, it was $85.56 \%$. There was a difference of $40 \%$ infection in between FDR and FDNR. In Paba, percent hill infection of FDNR was $87.78 \%$ whereas in FDR, it was $44.45 \%$. The difference in between FDNR and FDR was $43.33 \%$ in Paba. Kobayashi et al. (1997) also studied the incidence of ShB and primary inocula and found that the number of diseased hills was higher in the plots with debris than that in the plots without debris. The percentage of diseased hill in the plots without plant debris reached to $3.9 \%$ by one month after heading, whereas in plots containing plant debris at the rate of $2 \mathrm{~kg}$ and $4 \mathrm{~kg}$ per $35 \mathrm{~m}^{2}$, the values were 11 and $18 \%$ respectively (Kobayashi et al., 1997). Figure 3 shows the percent reduction of hill infection of ShB at maximum tillering stage. Maximum 63.01\% reduction in hill infection was found in Tanore, whereas significant reduction in hill infection was found in Godagari (46.75\%). Similarly the reduction in the ShB incidence was $49.36 \%$, found in Paba due to removal of floating debris from the field before transplanting. Disease development from sclerotia present in the soil however, depends on cultivar reaction, cultural practices and the micro-environment within the canopy, among other factors at maximum tillering to booting stage (Ui et al., 1976).

Table 2. Effect of floating debris removal on the incidence of rice sheath blight disease ( $\%$ hill infection) at maximum tillering stage.

\begin{tabular}{lccc}
\hline \multirow{2}{*}{ Treatment } & \multicolumn{3}{c}{ Disease incidence (\%) } \\
\cline { 2 - 4 } & Tanore & Godagari & Paba \\
\hline FDR & 30 & 45.56 & 44.45 \\
FDNR (Control) & 81.11 & 85.56 & 87.78 \\
Difference & 51.11 & 40 & 43.33 \\
Significance & $*$ & $*$ & $*$ \\
$(\mathrm{P}=0.05)$ & & & $*$ \\
\hline
\end{tabular}

DAT=Days after transplanting, FDR=Floating debris removed and FDNR=Floating debris not removed.

* Significant at the $5 \%$ level by paired t-test.

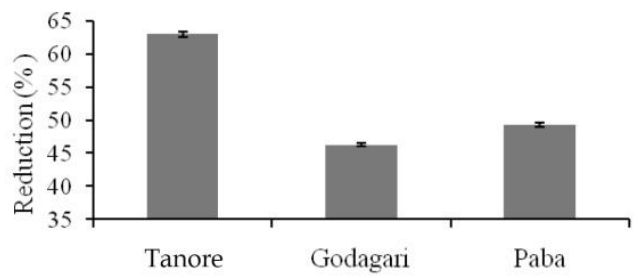

Fig. 3. Reduction of hill infection in FDR plots over FDNR in different locations at maximum tillering stage. 
Table 3 shows the effect of removal of floating debris on the incidence of rice ShB at maturity stage. It was recorded that percent tiller infection was higher in FDNR plot than that of FDR plot at maturity stage in the fields of Tanore, Godagari and Paba. The percent tiller infection was $2.37 \%$ in FDR plots whereas in FDNR, it was $6.48 \%$ in Tanore. Thus there was a difference of $4.11 \%$ infection in between FDR and FDNR. In Godagari, the percent tiller infection was $3.26 \%$ in FDR plots whereas in FDNR, it was $6.39 \%$. Thus there was a difference of $3.13 \%$ infection in between FDR and FDNR. At the same time, percent tiller infection of FDNR was $6.93 \%$ whereas in FDR, it was $3.39 \%$ observed in Paba. The difference between FDNR and FDR was 3.54\% in Paba. It was observed that difference between FDR and FDNR were significant at all the locations. Figure 4 shows the percent reduction of tiller infection of ShB disease at maturity stage. In Tanore, $63.42 \%$ reduction in tiller infection was found. A similar significant reduction in tiller infection was also found in Godagari $(48.98 \%)$. The reduction in ShB incidence was $51.08 \%$, found in Paba due to removal of floating debris from the field before transplanting. Kobayashi et al. (1997) also found that the plots with sclerotia showed greater number of diseased hills in proportion to the number of sclerotia than the plots without sclerotia. Inoculum potential of sclerotia was about three times as much as that of plant debris. These result suggested that mycelium in plant debris may play a role as primary inocula of the disease.

Table 4 shows the effect of removal of floating debris on the yield performance of Gutiswarna variety due to $\mathrm{ShB}$ disease of rice after harvesting. The rate of reduction in ShB incidence was similar in all locations. However, there was little numerical differences. Yield performance of Gutiswarna due to ShB disease of rice was higher in FDR plot than that of FDNR plot at maturity stage in the fields of Tanore, Godagari and Paba.
The average yield of three fields was 4.79 $t^{t} a^{-1}$ in FDR plot, whereas in FDNR, it was $4.18 \mathrm{t} \mathrm{ha}^{-1}$ in Tanore. Thus there was an yield difference of $0.61 \mathrm{t} \mathrm{ha}^{-1}$ in between FDR and FDNR plots. Figure 5 shows that the reduction in yield was $12.73 \%$ at Tanore. In Godagari, the average yield of three fields was $4.43 \mathrm{tha}^{-1}$ in FDR plot but $4.14 \mathrm{tha}^{-1}$ in FDNR. Thus, there was a difference of 0.29 $\mathrm{t} \mathrm{ha}^{-1}$ in between FDR and FDNR. In Godagari, $6.54 \%$ yield reduction was observed. At the same time, the average yield of FDNR plot was $3.80 \mathrm{t} \mathrm{ha}^{-1}$ in Paba. It was $4.15 \mathrm{t} \mathrm{ha}^{-1}$ in FDR. Difference in yield between FDNR and FDR was $0.35 \mathrm{t} \mathrm{ha}^{-1}$ in Paba. Consequently $8.43 \%$ yield reduction due to $\mathrm{ShB}$ incidence was found in Paba as a result of removal of floating debris from the field before transplanting. The best way to manage the disease would be to reduce the inocula through practices convenient to the farmers (Ou, 1985; Shahjahan et al., 1987).

Figure 6 and 7 show the relationship between the percent tiller infection of ShB disease and yield of Gutiswarna was established through critical point model for FDR and FDNR plots. Yield was affected by the presence of ShB infection in the tillers significantly reduced the grain yield in FDNR plots. The regression lines indicated that decrease in yield was associated with the increase of ShB incidence in the tillers. There was negative relationship between tiller infection and grain yield of rice with every unit increase in tiller infection, there was a corresponding yield loss of 0.46 units of grains in FGR plots. It is evident from the regression equation that the grain yield was $6.75 \mathrm{tha}^{-1}$ in the FDNR plots when there was no infections but infection in the tillers reduced the grain yield by 0.41 unit for every unit increase in tiller infection. The relationship between $X$ (random variable) and Y (dependent variable) was negative. The $R^{2}$ value proved that the negative contribution of $\mathrm{X}$ on $\mathrm{Y}$ was significant. 
Table 3. Effect of floating debris removal on the incidence of rice sheath blight disease ( $\%$ tiller infection) at maturity stage.

\begin{tabular}{lccc}
\hline \multirow{2}{*}{ Treatment } & \multicolumn{3}{c}{ Disease incidence (\%) } \\
\cline { 2 - 4 } & Tanore & Godagari & Paba \\
\hline FDR & 2.37 & 3.26 & 3.39 \\
FDNR (Control) & 6.48 & 6.39 & 6.93 \\
Difference & 4.11 & 3.13 & 3.54 \\
$\begin{array}{l}\text { Significance } \\
(\mathrm{P}=0.05)\end{array}$ & $*$ & $*$ & $*$ \\
\hline
\end{tabular}

FDR=Floating debris removed and FDNR=Floating debris not removed. * Significant at the $5 \%$ level by paired $t$-test.

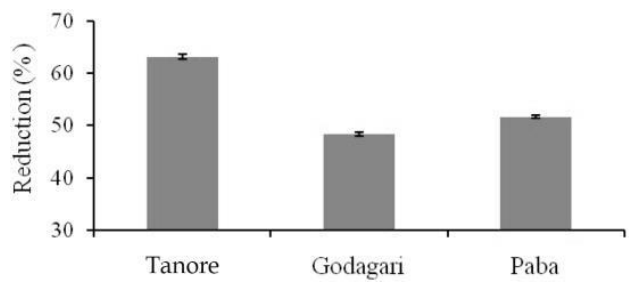

Fig. 4. Reduction of tiller infection in FDR plots over FDNR in different locations at maturity stage.

Table 4. Effect of removal of floating debris on sheath blight and yield of rice.

\begin{tabular}{lccc}
\hline \multirow{2}{*}{ Treatment } & \multicolumn{3}{c}{ Yield $\left(\mathrm{t} \mathrm{ha}^{-1}\right)$} \\
\cline { 2 - 4 } & Tanore & Godagari & Paba \\
\hline FDR & 4.79 & 4.43 & 4.15 \\
FDNR (Control) & 4.18 & 4.14 & 3.80 \\
Difference & 0.61 & 0.29 & 0.35 \\
Significance & $*$ & $*$ & $*$ \\
$(\mathrm{P}=0.05)$ & & & \\
\hline
\end{tabular}

FDR=Floating debris removed and FDNR=Floating debris not removed. * Significant at the $5 \%$ level by paired t-test.



Fig. 5. Yield reduction in FDR plots over FDNR by sheath blight due to presence of floating debris at different locations.

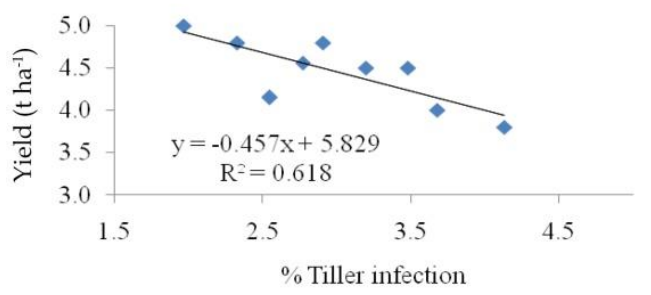

Fig. 6. Correlation between tiller infection at maturity stage and yield in FDR plot.

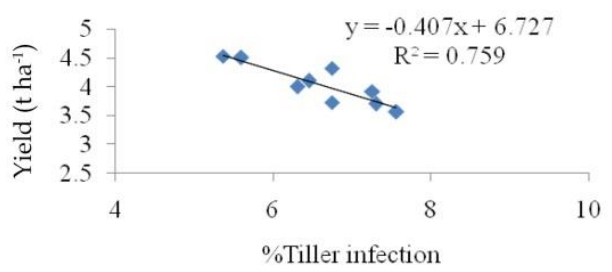

Fig. 7. Correlation between tiller infection at maturity stage and yield in FDNR plots.

\section{CONCLUSION}

The highest hill infection was found in FDNR (Floating debris not removed) plots than that of FDR (Floating debris removed) plots in the fields. Removal of debris floating on the irrigation/rain water in the field after final land preparation (before transplanting)had significant impact on the lesser development of ShB disease. Yield of Gutiswarna was higher in FDR plot than that of FDNR plot at maturity stage. There was low incidence of ShB in FDR plots. Inoculum potential of sclerotia and mycelia associated with floating debris need to be assessed in the rice fields.

\section{ACKNOWLEDGEMENT}

This study was the part of the corresponding author's PhD dissertation. The author acknowledges the scholarship and financial support given by NATP, BARC, Dhaka and 
research facilities provided by Plant Pathology Division, BRRI, Gazipur, Bangladesh.

\section{REFERENCES}

AIS, Krishi Diary. 2016. Agricultural Information Service, Khamarbari, Farmgate, Dhaka 1215, Bangladesh.

AIS, Krishi Diary. 2019. Agricultural Information Service, Khamarbari, Farmgate, Dhaka 1215, Bangladesh.

Ali, M A, M M Rahman, M A Latif, M Hossain, N R Sharma, S Akter, T A Mia and M A Nahar. 2003. Survey of rice sheath disease caused by different Rhizoctoniasp. in Bangladesh. In: Paper presented in the stakeholder workshop on Rice sheath blight disease complex at BRRI Gazipur on 3 December, 2003.

Anees, M, V Edel-Hermann and C Steinberg. 2010. Build up of patches caused by Rhizoctonia solani. Soil Biology and Biochemistry 42: 1661-1672.

Anonymous. 2006a. Bangladesh Arothonoitik Sameekha. Finance Division, Ministry of Finance, The Secretariat, Govt. of the Peoples Republic of Bangladesh, Dhaka, Bangladesh.

Anonymous. 2006b. World Rice Statistics. International Rice Research Institute, Res. Inst. http://www. irri.org/science/wrs. Accessed in July 2006.

Anonymous. 2010. Adhunik Dhaner Chash (Bangla version). Publication no. 5, 15th Edition, Bangladesh Rice Research Institute, Gazipur 1701, Bangladesh.

BBS (Bangladesh Bureau of Statistics). 2014. Statistical Yearbook Bangladesh. Ministry of Planning, Government of the People's Republic of Bangladesh, Sher-E-Bangla Nagar, Bangladesh.

Brooks, S A. 2007. Sensitivity to a Phytotoxin from Rhizoctonia solani correlates with sheath blight susceptibility in Rice. Phytopathology 97: 12071212.

Castilla, N P, R M Leano, F A Elazegui, P S Teng and S Savary. 1996. Effects of plant contacts, inoculation pattern, leaf wetness regime, and nitrogen supply on inoculum efficiency in rice sheath blight. J. Phytopathol. 144: 187-192.

Damicone, J R, M V Patel and W F Moore. 1993. Density of sclerotia of Rhizoctonia solani and incidence of sheath blight in rice fields in Mississippi. Pl. Dis. 77 (3): 257-260.

Hashiba, T and S Mogi. 1976. Development changes in sclerotia of the sheath blight fungus. Phytopathology 65: 159-62.

Kobayashi, T, T W Mew and T Hashiba. 1997. Relationship between incidence of rice sheath blight and primary inoculums in the Philippines: Mycelia in plant debris and sclerotia. Ann. Phytopathol. Soc. Jap. 63: 324-327.
Kumar, K K, S K R Yellareddygari, M S Reddy, JW Kloepper, KS Lawrence, XG Zhou, H Sudini, D E Groth, S K Raju and ME Miller. 2012. Efficacy of Bacillus subtilis (MBI 600) against sheath blight caused by Rhizoctonia solani and on growth and yield of rice. Rice Science 19: 55-63.

Lee, F N and M C Rush. 1983. Rice sheath blight: A major rice disease. Plant Disease 67 (7): 829-32.

Li, Di-q, Q-y Tang, Y-b Zhang, J-q Qin, H Li, L-j Chen, S-h Yang, Y-b Zouand S-b Peng. 2012. Effect of nitrogen regimes on grain yield, nitrogen utilization, radiation use efficiency, and sheath blight disease intensity in super hybrid rice. Journal of Integrative Agriculture 11: 134-143.

Miah, S A and A K M Shahjahan. 1987. Mathe Dhaner Rog Nirnoy O Tar Protikar (Bangla Version). Bangladesh Rice Research Institute, Gazipur. Bangladesh. Pp. 60.

Miyakie, I. 1910. Studies über die Pilze der Reispflanzen in Japan. J. Coll. Agric. Imperial Univ. Tokyo 2: 237-276.

Ogoshi, A. 1996. Introduction of the genus Rhizoctonia. In: B Sneh, S Jabaji-Hare, S Neate and G Dijst (eds.), Rhizoctonia Species: Taxonomy, Molecular Biology, Ecology, Pathology and Disease Control. Kluwer Academic Publishers, Dordrecht, NL. Pp. 1-9.

Ou, S H. 1985. Rice disease. $2^{\text {nd }}$ Ed. Commonwealth Mycological Institute Kew, Surrey, England. Pp. 272-86.

Salam, M U, S M A Hossain, J K Biswas and A J Mridha. 2014. Managing the unmanageable: rice variety technology for future challenging food security in Bangladesh. Extended abstract in the 'Agronomic visions in challenging future', the proceedings of the $13^{\text {th }}$ conference of the Bangladesh Society of Agronomy, 20 September 2014, Bangladesh Rice Research Institute (BRRI), Gazipur, Bangladesh.

Shahjahan, A K M, N Fabellar and T W Mew. 1987. Nitrogen level, cultivar and Rhizoctonia solani isolates effect on sheath blight development. International Rice Research Newsletter 12 (3): 27-28.

Shahjahan, A K M, N R Sharma, H U Ahmed and S A Miah. 1986. Yield loss in modern rice varieties of Bangladesh due to sheath blight. Bangladesh J. of Agricutural Research 11 (2): 82-90.

Sharma, N R, P S Teng and F M Olivares. 1994. Effect of inoculum source on sheath blight disease development and yield in rice. Bangladesh J. Plant Pathol. 10 (1 \& 2): 17-20.

Su, P, X Liao, Y Zhang and H Huang. 2012. Influencing factors on rice sheath blight epidemics in integrated rice-duck system. Journal of Integrative Agriculture 11: 1462-1473. 
Tsai, Y N, M J Lin and W H Ko. 2012. A simple method for production of uniform inoculum of Rhizoctoniasolaniwith strong pathogenicity. Biocatalysis and Agricultural Biotechnology 1: 85-88.

Ui, T, T Naiki and M Akimoto. 1976. A seving-floatation technique using hydrogen peroxide solution for determination of sclerotial population of
Rhizoctoniasolani Kuhn in soil. Ann. Phytopath. Soc. Japan 42: 46-48.

Wu, W, J Huang, K Cui, L Nie, Q Wang, F Yang, F Shah, F Yao and S Peng. 2012. Sheath blight reduces stem breaking resistance and increases lodging susceptibility of rice plants. Field Crops Research 128: 101-108. 